Original Article

\title{
The JAK2V617F Point Mutation Increases the Osteoclast Forming Ability of Monocytes in Patients with Chronic Myeloproliferative Neoplasms and Makes their Osteoclasts more Susceptible to JAK2 Inhibition
}

Emmanouil Spanoudakis ${ }^{1}$, Menelaos Papoutselis ${ }^{1}$, Ioanna Bazdiara ${ }^{1}$, Eleftheria Lamprianidi ${ }^{1}$, Xrisa Kordella ${ }^{1}$, Constantinos Tilkeridis ${ }^{2}$, Costas Tsatalas ${ }^{1}$ and Ioannis Kotsianidis ${ }^{1}$.

${ }^{1}$ Department of Hematology, Democritus University of Thrace, Alexandroupolis, Greece.

${ }^{2}$ Department of Orthopedics, Democritus University of Thrace, Alexandroupolis, Greece.

Competing interests: The authors have declared that no competing interests exist.

Abstract. $J A K 2 \mathrm{~V} 617 \mathrm{~F}$ is a gain of function point mutation that occurs in Myeloproliferative Neoplasm (MPN) patients and deranges their hemopoiesis at cellular level. We speculate that hyperfunctioning JAK2 can modify osteoclast (OCL) homeostasis in MPN patients. We studied 18 newly diagnosed MPN patients and four age-matched normal donors (ND). Osteoclast forming assays started from selected monocytes also and under titrated concentrations of the JAK2 Inhibitor AG-490 (Tyrphostin). Genomic DNA was extracted from the formed osteoclasts, and the $J A K 2 V 617 F / J A K 2 W T$ genomic DNA ratio was calculated. OCLs formed from monocytes derived from heterozygous (Het) for the $J A K 2 V 617 F$ mutation MPN patients, were three times more compared to those from $J A K 2$ wild type (WT) MPN patients $(\mathrm{p}=0,05)$ and from ND as well $(\mathrm{p}=0,03)$. The ratio of $J A K 2 \mathrm{~V} 617 \mathrm{~F} / J A K 2 W T$ genomic DNA was increased in OCLs compared to the input monocyte cells showing a survival advantage of the mutated clone. In comparison to ND and JAK2 WT MPN patients, OCLs from patients JAK2V617F (Het) were more susceptible to $J A K 2$ inhibition. These alterations in osteoclast homeostasis, attributed to mutated $J A K 2$, can deregulate the hemopoietic stem cell niche in MPN patients.

Keywords: JAK2V617F, Osteoclast, Myeloproliferative neoplasm.

Citation: Spanoudakis E., Papoutselis M., Bazdiara I., Lamprianidi E., Kordella X., Tilkeridis C., Tsatalas C., Kotsianidis I. The JAK2V617F point mutation increases the osteoclast forming ability of monocytes in patients with chronic myeloproliferative neoplasms and makes their osteoclasts more susceptible to JAK2 inhibition. Mediterr J Hematol Infect Dis 2018, 10(1): e2018058, DOI: http://dx.doi.org/10.4084/MJHID.2018.058

Published: November 1, 2018

Received: July 3, 2018

Accepted: September 16, 2018

This is an Open Access article distributed under the terms of the Creative Commons Attribution License (https://creativecommons.org/licenses/by-nc/4.0), which permits unrestricted use, distribution, and reproduction in any medium, provided the original work is properly cited.

Correspondence to: Emmanouil Spanoudakis, Assistant Professor of Hematology. Democritus University of Thrace, Area of Dragana, Alexandroupolis, Greece, PC: 68100. Tel: 00302551351512. E-mail: emmanouilspanoudakis@ yahoo.com

Introduction. Osteoclasts (OCLs) are bone resorting cells of hemopoietic origin. The balanced function between osteoclasts and osteoblasts determines bone homeostasis. Osteoblasts are considered important cells for the hemopoietic stem cell (HSC) niche formation and regulation, ${ }^{1}$ while osteoclasts are considered dispensable cells in this setting. Their role is to mobilise hemopoietic progenitor cells towards the peripheral blood especially under stress conditions. $^{2-6}$

$J A K 2$ is an intracellular kinase, a cellular hub, that acts as a second mediator of intracellular signaling from a variety of cytokine and hormone receptors. ${ }^{7,8}$ Pharmacological inhibition of the $J A K 2$ kinase reduces osteoclast bone resorting activity, ${ }^{9-12}$ suggesting that the intact JAK2 function is essential for normal osteoclast 
function.

The JAK2V617F is a gain of function point mutation that often occurs in patients with myeloproliferative neoplasms (MPN) and deranges basic cellular functions of their hemopoietic cells. ${ }^{13,14}$ JAK2V617F arises in an early myeloid progenitor cell, cells ancestor to OCLs. Except intrinsic stem cell defects, HSC niche deregulation in $J A K 2 V 617 F$ mutated mice models of MPN contributes equally to MPN disease evolution. ${ }^{1,15}$

Therefore we speculate that genetically modified $J A K 2$, as it occurs in MPN patients, can slightly modify osteoclast homeostasis in a way that deregulates hematopoietic stem cell niche homeostasis.

\section{Patient's Samples and Materials.}

Approximately, $60 \mathrm{ml}$ of peripheral blood was drawn, after informed contest form was signed, from 18 newly diagnosed MPN patients (14 essential thrombocythemia, two primary myelofibrosis, two polycythemia vera diagnosed according to 2008 WHO criteria) and from 4 agematched normal donors (ND). Positive selection of CD14+ monocyte cells was performed by using immunomagnetic beads separation technique (MiltenyiBiotec). The selective JAK2 inhibitor, TyrphostinAG-490, was provided by Sigma Diagnostics and was dissolved in DMSO. This study was approved by the local ethics committee and conducted according to the principles of the declaration of the Helsinki.

JAK2V617F mutation detection in our patient's cohort. Genomic DNA was extracted from whole blood (QIAGEN), and $25 \mathrm{ng}$ of gDNA were subjected to Allele-specific PCR (ASO-PCR) for the detection of the JAK2V617F mutation according to the protocol described by Baxter et al., slightly modified. Restriction Length Polymorphism method (RFLP) by using the BsaXI restriction enzyme, was performed in all positive for the JAK2V617F mutation samples, to determine its presence in heterozygous or homozygous status.

Osteoclast (OCL) forming assays from monocyte cells derived from MPN patients. $2 \times 10^{5}$ positively selected monocyte cells, after checked for purity by flow cytometry, were suspended in a MEM medium $+10 \%$ Fetal Calf Serum, supplemented with optimum concentrations of osteclastogenic cytokines (RANKL $25 \mathrm{ng} / \mathrm{ml}$ and M-CSF 50 $\mathrm{ng} / \mathrm{ml}$ ) and then they were plated in a 48 -flat bottom well plate. The half medium exchange was performed twice weekly, and the number of formed OCLs was scored under inverted microscope by using TRAP assays (Sigma Diagnostics) after staying 14 days in culture.

Quantitative Real-Time PCR (RT-PCR) for JAK2V617F/JAK2WT genomic DNA ratio measurement. Genomic DNA was extracted (QIAGEN) from both the input for OCL forming assays monocyte cells as well as from the OCLs that they were finally formed from them. $J A K 2 V 617 F / J A K 2 W T$ genomic DNA ratio was calculated by using the Taqman based JAK2MutaQuant Kit (IPSOGEN). Briefly, a pair of FAM-tracked hybridisation probes was used in two different reaction tubes, one of them specific for the G1849T JAK2 mutation and the other specific for the wild type sequence, together with a $J A K 2 \mathrm{gDNA}$ specific pair of primers. Appropriate serial dilutions of known numbers of mutated and wild type JAK2 transcripts were used in order to set the calibration plot. All assays were performed on an ABI Prism7500 analyser (AppliedBiosystems).

OCL forming assays in the presence of the JAK2 inhibitorAG-490(Tyrphostin). Initially, titration of the inhibitory dose of AG-490 on OCL formation assays was performed. Selected monocytes from three normal donors started OCL forming assays in the presence of serial dilutions of AG-490 dissolved in DMSO; range $0.01-100 \mu \mathrm{M}$. The $50 \%$ Inhibitory concentration (IC50) was determined at $20 \mu \mathrm{M}$ (Figure 2A). Then OCL forming assays were started from MPN patient's monocytes as previously described, and concurrently OCL forming assays in the presence of $2 \mu \mathrm{M}$ and $20 \mu \mathrm{M}$ of the JAK2 inhibitor AG-490 (Tyrphostin) dissolved in DMSO were also started.

CTX $\beta$ in serum measurement by ELISA and Colony Forming Assays from CD34 selected cells from the peripheral blood. CTX $\beta$ levels in whole blood serum were measured by ELISA ( $\beta$ crossLaps/serum kit, Roche Diagnostics). Data are expressed as $\mathrm{ng} / \mathrm{ml}$. 

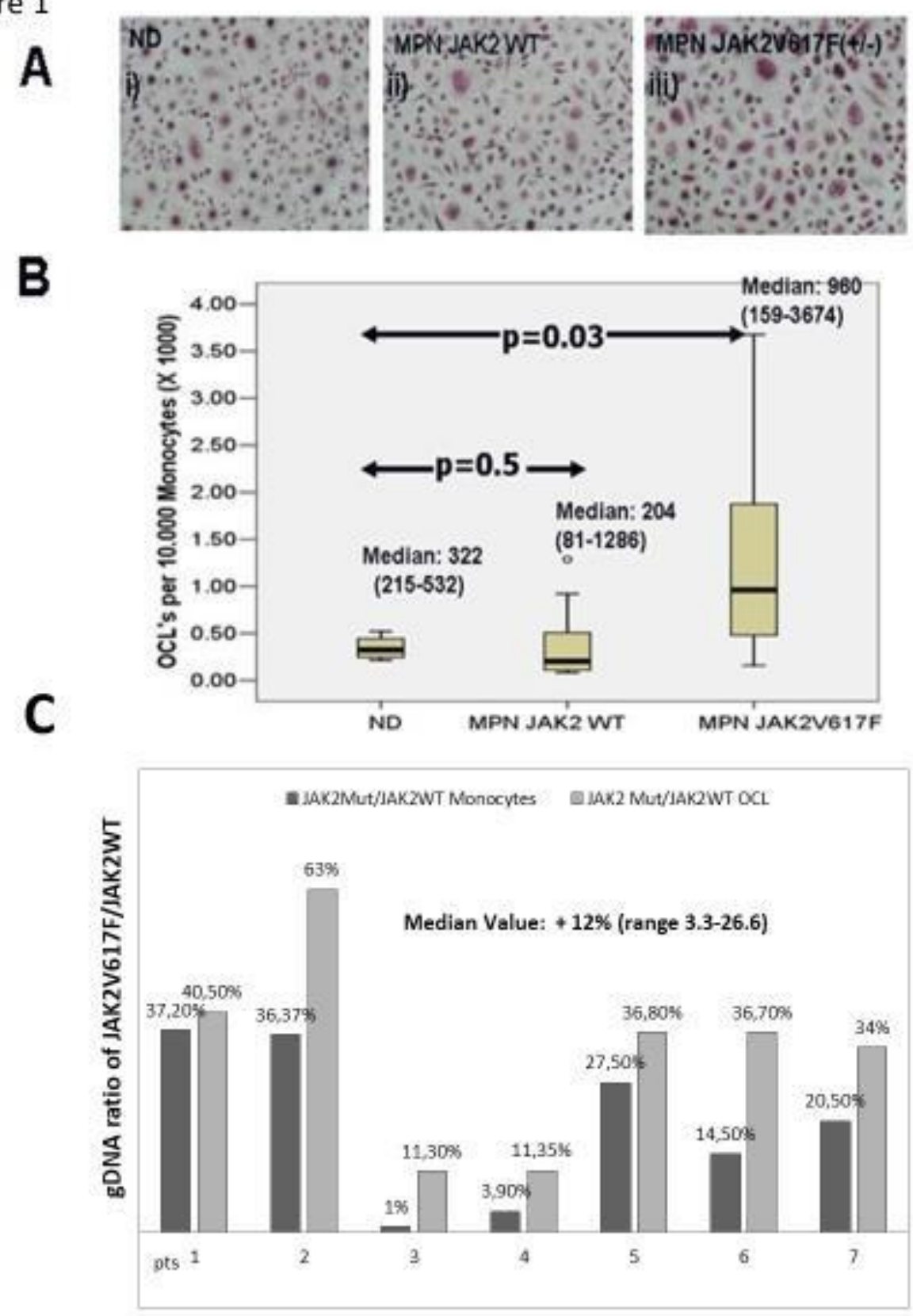

Figure 1. Osteoclast Forming assays and ratio of JAKWT/JAK2V617FgDNA copies in monocytes and in the osteoclasts derived from them. A. An example of TRAP + osteoclasts derived from selected monocytes after staying in OCL forming assays for 14 days i) normal donors, ii) JAK2 WT MPN patients, iii) JAK2V617F (Het) MPN patients. B. Osteoclasts formed from the same number of monocyte cells under optimum osteoclastogenic conditions (M-CSF and RANKL) are significantly more for JAK2V617F (Het) MPN patients compared to normal donors (Mann-Whitney, $\mathrm{p}=0,03$ ). C. Ratio of JAKWT/JAK2V617FgDNA copies were measured by Taq-man based Real-Time PCR assays in the input monocyte cells and in the osteoclasts that were finally derived from them. The osteoclasts overgrowth noted in JAK2V617F (Het) MPN patients is partly due to the overgrowth of the mutated clone (median expansion: 12\%, range 3,3-26,6\%).

Statistical analysis. All values represent median values (min-max). Comparisons between groups were performed by using the Mann-Whitney for unpaired and the Wilconxon Rank test for paired samples. Statistical significance was considered at the level of $\mathrm{p}<0.05$ value. The SPSS-13 statistical package was used for statistical analysis.

\section{Results.}

JAK2 mutation status detection. Nine MPN patients out of eighteen were found positive for the JAK2V617F point mutation (2 PV patients, $1 \mathrm{IMF}$ patient and 6 ET patients) while nine MPN patients ( $8 \mathrm{ET}$ patients and $1 \mathrm{IMF}$ patient), and the four ND were $J A K 2 V 617 F$ negative. Apparently, two JAK2 WT patients were tested positive for the CALR mutation and none positive for cMPL mutation. We then subjected the samples that were 
positive for $J A K 2 V 617 F$ mutation to RFLP assays by using the BsaXI restriction enzyme, to determine their ploidy status. All out of nine patients tested were heterozygous for the $J A K 2 V 617 F$ point mutation.

The presence of the JAK2V617F point mutation enhances in-vitro OCL forming ability. OCLs were formed from monocyte cells derived from ND, and JAK2 mutated or unmutated MPN patients (an example is given in Figure 1A). OCLs derived from heterozygous for the $J A K 2 V 617 F$ mutation (Het) MPN patients, were significantly more compared to those from the JAK2 wild type (WT) MPN patients and ND as well; Median OCLs per 10.000 monocytes, (min- max): JAK2V617F (Het) MPN: 960 (159-3674), JAK2 WT MPN: 204 (811286) and $\mathrm{p}=0.03$ Mann-Whitney test (Figure 1B). Considering ND the Median (min-max) OCLs per 10.000 monocytes were: 322 (215-522) and $\mathrm{p}=0.05$ when compared to JAK2V617F (Het) MPN patients (Figure 1B).

OCLs derived from JAK2V617F(Het) monocytes are enriched for the mutated clone compared to the input monocyte cells reflecting an increased outgrowth of the JAK2 V617F mutated clone. We then performed quantitative Taqman based RTPCR assays at genomic DNA level, in both the input monocyte cells and in the OCLs that were finally derived from them, aiming to clarify whether the increased OCL formation noted from $J A K 2 V 617 F$ (Het) MPN monocytes reflects outgrowth of the wild type or the mutated clone. In all out of seven JAK2V617F (Het) MPN patients successfully tested, the ratio of $J A K 2 V 617 F / J A K 2 W T$ genomic DNA was increased in the OCLs fraction compared to the input monocyte cells. The median enrichment of OCLs for the JAK2V617F mutated clone was $12 \%$ (range: $3.3 \%-26 \%$ ) and $\mathrm{p}<0.01$, Wilconxon Rank test (Figure 1C).

No evidence by CTX $\beta$ of increased OCL activity in JAK2 V617F patients. The ability of JAK2 (Het) for higher OCL formation ex vivo poses the question if these patients have in higher levels of osteoclast activity in vivo. Therefore we quantified in serum from our MPN patients the levels of CTX $\beta$ by ELISA but we cannot find any difference among groups [median Value (minmax) JAK2 (Het): 1,013(0,9-2,1 ng/ml) JAK2
WT: $1,014(0,78-2,1 \mathrm{ng} / \mathrm{ml}, \mathrm{p}=0,69$ Data not shown).

In Vitro Osteoclastogenesis from monocyte cells derived from MPN patients is dependent upon $J A K 2$ function. In order to address the dependence of osteoclastogenesis from JAK2 kinase in mutated and unmutated cells we performed OCL forming assays under titrated inhibition of the JAK2 kinase by the selective JAK2 inhibitor AG490. We determined IC50 in OCL forming assays performed from $3 \mathrm{ND}$ monocytes at $20 \mu \mathrm{M}$ (Figure 2A). Afterwards, we performed OCL inhibition assays under titrated concentrations of AG490 at $2 \mu \mathrm{M}$ and $20 \mu \mathrm{M}$ in MPN patients. OCL inhibition is dose dependent in both groups of MPN patients (Table 1) but it has a significantly suppressing effect on OCL formation only in JAK2 (Het) MPN patients compared to ND. Of Note, at the higher inhibitory concentration of $20 \mu \mathrm{M}$ OCL formation in samples from JAK2V617F (Het) patients was significantly reduced compared to ND (Table 1, $\mathrm{p}=0,02)$ and compared to JAK2 WT MPN patients as well $(\mathrm{p}=0,05)$. There was no statistically significant difference between ND and JAK2 WT MPN ( $p=0,28$, Figure 2B).

Discussion. In this study, we demonstrated that cells carrying the $J A K 2 V 617 F$ point mutation are more efficient for osteoclast formation compared to cells carrying the JAK2 WT genotype. Monocytes derived from JAK2V617(Het) MPN patients can form 3 times more OCLs compared to the monocyte cells carrying the JAK2 WT genotype from both MPN patients and ND. Because input monocyte cells from $J A K 2 V 617$ (Het) patients is a mixture of cell clones carrying both JAK2V617F and JAK2 WT DNA copies we performed real-time PCR at genome level to see whether the OCL overgrowth is due to the preferential expansion of either of the two clones. We demonstrated that the percentage of mutated JAK2 DNA copy numbers in the OCL fraction was increased compared to the input monocyte cell fraction by a median value of $12 \%$. In our culture system the concentrations of RANKL and MCSF is optimum for monocyte differentiation to osteoclasts, and therefore cells committed to the OCL lineage are attached to the bottom of the plate, and they will mature to OCL unless they do not survive. Hence, the enrichment of OCL cell fraction for V617F mutated clones 
Figure 2
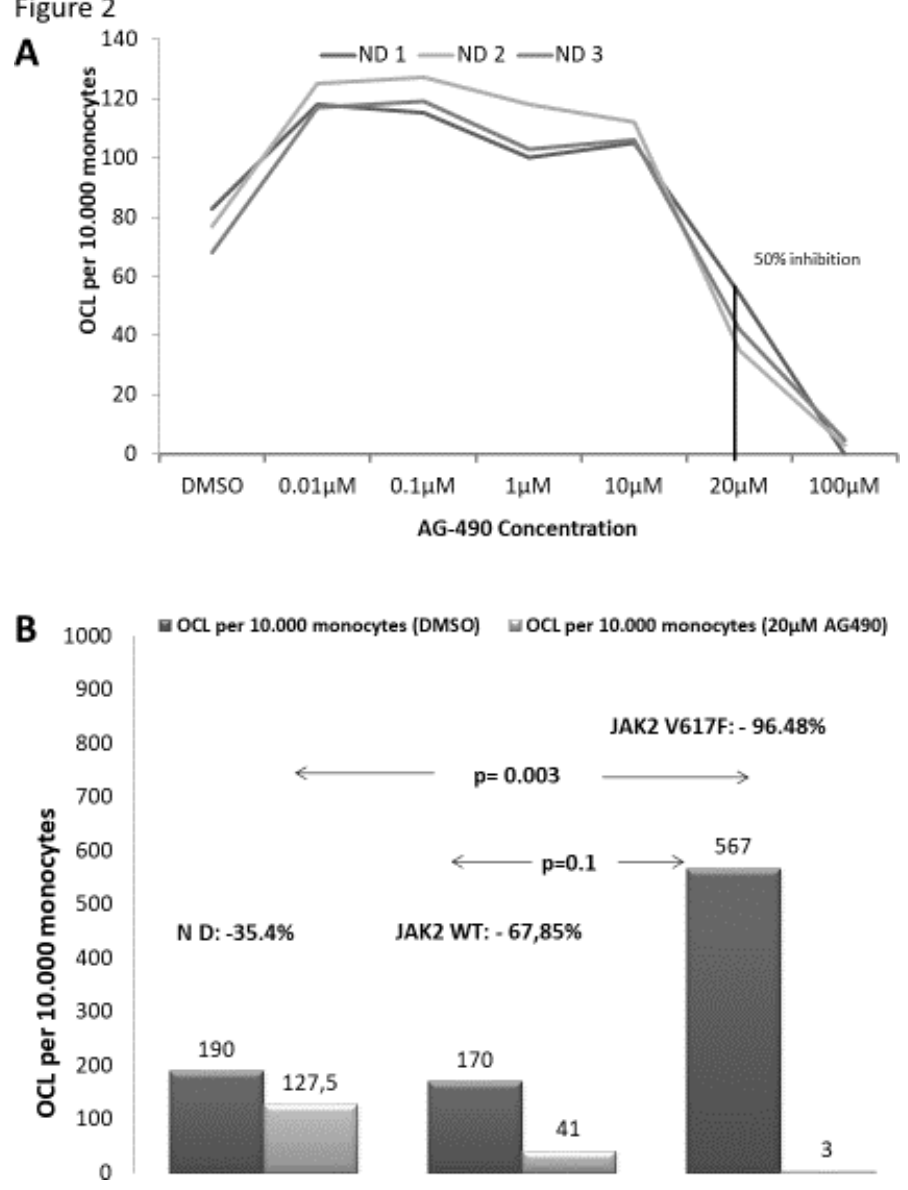

Figure 2. Inhibition of OCL forming assays with the JAK2 inhibitor AG-490 (Tyrphostin). A. Osteoclast forming assays were performed under titrated concentrations of the selective JAK2 inhibitor AG-490 dissolved in DMSO. Monocyte cells from 3 ND were used in order to determine the $50 \%$ inhibitory concentration of AG-490. The 50\% inhibitory concentration was $20 \mu \mathrm{M}$. B. Osteoclast forming assays from selected monocyte cells derived from MPN patients under the concentration of $2 \mu$ Mand of $20 \mu \mathrm{M}$ of AG-490. Compared to ND osteoclast formation was almost completely abolished in JAK2V617F (Het) MPN patients and was equally reduced in ND and in JAK2 WT MPN patients.

Table 1. Median OCL formed under titrated inhibition with the JAK2 inhibitor AG490.

\begin{tabular}{|c|c|c|c|c|c|}
\hline & $\begin{array}{c}\mathrm{AG} 490 \\
0 \mu \mathrm{M}\end{array}$ & $\begin{array}{c}\mathrm{AG} 490 \\
2 \mu \mathrm{M}\end{array}$ & $\begin{array}{c}\text { AG490 } \\
20 \mu M\end{array}$ & $\begin{array}{c}\text { Median \% of } \\
\text { Reduction } \\
0 \mu \mathrm{Mvs} 2 \mu \mathrm{M}\end{array}$ & 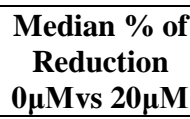 \\
\hline ND (Median, min-max) & $\begin{array}{c}201 \\
156-232\end{array}$ & $\begin{array}{c}190 \\
156-428\end{array}$ & $\begin{array}{c}127 \\
79-214\end{array}$ & $\begin{array}{c}0 \% \\
0-12 \\
\end{array}$ & $\begin{array}{l}35,4 \% \\
29-50\end{array}$ \\
\hline JAK2 WT(Median, min-max) & $\begin{array}{c}204 \\
81-1286 \\
\end{array}$ & $\begin{array}{c}170 \\
80-487 \\
\end{array}$ & $\begin{array}{c}41 \\
0-250 \\
\end{array}$ & $\begin{array}{l}11 \% \\
1-81 \\
\end{array}$ & $\begin{array}{l}84,4 \% \\
34-100 \\
\end{array}$ \\
\hline JAK2 V617F (Median, Min-max) & $\begin{array}{c}960 \\
159-3674\end{array}$ & $\begin{array}{c}567 \\
70-2647\end{array}$ & $\begin{array}{c}3 \\
0-250\end{array}$ & $\begin{array}{c}27 \% \\
11-55\end{array}$ & $\begin{array}{l}97,4 \% \\
45-100\end{array}$ \\
\hline
\end{tabular}

shows a proliferation/survival advantage of the mutated clone compared to the JAK2 WT clones.

We then tried to address if this ex vivo effect of JAK2V617F on OCL formation has a detectable in vivo effect. Therefore we assessed osteoclastogenic activity in the serum of our patients by measuring $\mathrm{CTX} \beta$ levels finding no difference between both groups. These data suggest that the in vivo effect of JAK2V617F on OCL formation and finally on the bones is not so robust in order to be detected by CTX $\beta$ levels.
In order to provide further insight to the dependence of MPN osteoclastogenesis from the $J A K 2$ kinase function, we performed OCL forming assays under titrated pharmacological inhibition of the $J A K 2$ kinase with the selective $J A K 2$ inhibitor AG-490 (Tyrphostin). We noted that osteoclastogenesis from cells carrying the $J A K 2 V 617 F$ point mutation is more susceptible to $J A K 2$ kinase inhibition than osteoclastogenesis from cells that are carrying the wild type $J A K 2$ kinase in a dose dependent manner. Our data 
provide evidence for a therapeutic effect of JAK2 inhibitors in MPN patients through reversion of OCL deregulation.

Our data enforce a model of deregulated osteoclastogenesis in a disease characterised by the genetically modified JAK2 kinase. In this study, we found out that the acquisition of the $J A K 2 V 617 F$ point mutation in hematopoietic cells capable of osteoclastogenesis increases their OCL

\section{References:}

1. Sanchez-Aguilera A, Mendez-Fer S. The hematopoietic stem-cell niche in health and leukemia Cell. Mol. Life Sci. 2017, 74:579-590. https://doi.org/10.1007/s00018-016-2306-y PMid:27436341 PMCid:PMC5272896

2. Mansour A, Abou-Ezzi G, Sitnicka E, W Jacobsen SE, Wakkach A, Blin-Wakkach C. Osteoclasts promote the formation of hematopoietic stem cell niches in the bone marrow. J Exp Med. 2012 Mar 12;209(3):537-49. https://doi.org/10.1084/jem.20110994 PMid:22351931 PMCid:PMC3302238

3. Lymperi S, Ersek A, Ferraro F, Dazzi F, Horwood NJ. Inhibition of osteoclast function reduces hematopoietic stem cell numbers in vivo. Blood. 2011 Feb 3;117(5):1540-9. https://doi.org/10.1182/blood- 2010-05-282855 PMid:21131587

4. Miyamoto K, Yoshida S, Kawasumi M, Hashimoto K, Kimura T, Sato Y, Kobayashi T, Miyauchi Y, Hoshi H, Iwasaki R, Miyamoto H, Hao W, Morioka H, Chiba K, Kobayashi T, Yasuda H, Penninger JM, Toyama Y, Suda T, Miyamoto T. Osteoclasts are dispensable for hematopoietic stemcell maintenance and mobilization. J Exp Med. 2011 Oct 24; 208(11):2175-81. https://doi.org/10.1084/jem.20101890 PMid:22006978 PMCid:PMC3201203

5. Kollet O, Dar A, Shivtiel S, Kalinkovich A, Lapid K, Sztainberg Y, Tesio M, Samstein RM, Goichberg P, Spiegel A, Elson A, Lapidot T. Osteoclasts degrade endosteal components and promote mobilization of hematopoietic progenitor cells. Nat Med. 2006 Jun;12(6):657-64. https://doi.org/10.1038/nm1417 PMid:16715089

6. Flores C, Moscatelli I, Thudium CS, Gudmann NS, Thomsen JS Bruel A, Karsdal MA, Henriksen K, Richter J. Osteoclasts are not crucial for hematopoietic stem cell maintenance in adult mice. Haematologica 2013, 98(12):1848-1855. https://doi.org/10.3324/haematol.2013.089466 PMid:24097632 PMCid:PMC3856959

7. Rawlings JS, Rosler KM, Harrison DA, The JAK/STAT signaling pathway. J Cell Sci. 2004; 117: 1281- 1283. .https://doi.org/10.1242/jcs.00963 PMID: 15020666

8. Murray PJ, The JAK-STAT signaling pathway: input and output integration. J Immunol. 2007; 178: 2623-2629. https://doi.org/10.4049/jimmunol.178.5.2623 PMid:17312100

9. Kwak HB, Kim HS, Lee MS, Kim KJ, Choi EY, Choi MK, Kim JJ, Cho HJ, Kim JW, Bae JM, Kim YK, Park BH, Ha H, Chun CH, Oh J. Pyridone6, a pan-Janus-activated kinase inhibitor, suppresses forming ability, but these OCLs are also more vulnerable to $J A K 2$ kinase inhibition. This poses to us the challenge to extrapolate the underlying mechanism of increased osteoclastogenesis in JAK2V617F mutated cells and furthermore to perform OCL functional assays in a cohort of MPN patients enriched in patients homozygous for the JAK2 mutation. Targeting osteoclasts may be of value in MPN patients.

osteoclast formation and bone resorption through down-regulation of receptor activator of nuclear factor-kappaB (NF-kappaB) ligand (RANKL)-induced c-Fos and nuclear factor of activated $\mathrm{T}$ cells (NFAT) c1 expression. Biol Pharm Bull. 2009 Jan;32(1):45-50. https://doi.org/10.1248/bpb.32.45 PMid:19122279

10. Li CH, Zhao JX, Sun L, Yao ZQ, Deng XL, Liu R, Liu XY. AG490 inhibits NFATclexpression and STAT3 activation during RANKL induced osteoclastogenesis. Biochem Biophys Res Commun 2013 Jun 14: 435(4):533-9. https://doi.org/10.1016/j.bbrc.2013.04.084 PMid:23665018

11. Jin-il Park, Jennifer Lee, Mi-Ae Lim, Eun Kyung Kim, Sung Min Kim, JunGeolRyu, Jae Ho Lee, Seung-Ki Kwok, kyung-Su Park, HoYoun Kim, Sung-Hwan Park, Mi-La Cho. JAK2-STAT3 Blockade by AG490 Supresses autoimmune arthritis in mice via reciprocal regulation of T cells and Th17 cells. Journal of Immunology 2014; 192:4417-24. https://doi.org/10.4049/jimmunol.1300514 PMid:24688026

12. Murakami K, Kobayashi Y, Uehara S, Suzuki T, Koide M, Yamashita T, et al. A Jak1/2 inhibitor, baricitinib, inhibits osteoclastogenesis by suppressing RANKL expression in osteoblasts in vitro. PLoSONE 2017, 12(7): e0181126.

https://doi.org/10.1371/journal. pone.0181126

13. Mead AJ, Chowdhury O, Pecquet C, Dusa A, Woll P, Atkinson D, Burns A, Score J, Rugless M, Clifford R, Moule S, Bienz N, Vyas P, Cross N, Gale RE, Henderson S, Constantinescu SN, Schuh A, Jacobsen SE. Impact of germline JAKV617F mutation in human hematopoiesis. Blood. 2013 May 16;121(20):4156-65. https://doi.org/10.1182/blood-2012-05-430926 PMid:23535062

14. Passamonti F, Rumi E, Pietra D, Della Porta MG, Boveri E, Pascutto C, Vanelli L, Arcaini L, Burcheri S, Malcovati L, Lazzarino M, Cazzola M. Relation between JAK2 (V617F) mutation status, granulocyte activation, and constitutive mobilization of CD34+ cells into peripheral blood in myeloproliferative disorders. Blood. 2006 May 1;107(9):3676-82. https://doi.org/10.1182/blood-2005-09-3826 PMid:16373657

15. Arranz L, Sanchez-Aguilera A, Martin-Perez D, Isern J, Langa X, Tzankov A, Lundberg P, Muntion S, Tzeng YS, Lai DM, Schwaller J, Skoda RC, Mendez-Ferrer S (2014) Neuropathy of haematopoietic stem cell niche is essential for myeloproliferative neoplasms. 512, Nature Aug 2014; 78-81. https://doi.org/10.1038/nature13383 